

\section{DISCLAIMER}

This report was prepared as an account of work sponsored by an agency of the United States Government. Neither the United States Government nor any agency Thereof, nor any of their employees, makes any warranty, express or implied, or assumes any legal liability or responsibility for the accuracy, completeness, or usefulness of any information, apparatus, product, or process disclosed, or represents that its use would not infringe privately owned rights. Reference herein to any specific commercial product, process, or service by trade name, trademark, manufacturer, or otherwise does not necessarily constitute or imply its endorsement, recommendation, or favoring by the United States Government or any agency thereof. The views and opinions of authors expressed herein do not necessarily state or reflect those of the United States Government or any agency thereof. 


\section{DISCLAIMER}

Portions of this document may be illegible in electronic image products. Images are produced from the best available original document. 


\section{LEG A L NOTICE}

This report was prepared as an account of Government sponsored work. Neither the United States, nor the Commission, nor any person acting on behalf of the Commission:

A. Makes any warranty or representation, expressed or implied, with respect to the accuracy, completeness, or usefulness of the information contained in this report, or that the use of any information, apparatus, method, or process disclosed in this report may not infringe privately owned rights; or

B. Assumes any liabilities with respect to the use of, or for damages resulting from the use of any information, apparatus, method, or process disclosed in this report.

As used in the above, "person acting on behalf of the Commission" includes any employee or contractor of the Commission, or employee of such contractor, to the extent that such employee or contractor of the Commission, or employee of such contractor prepares, disseminates, or provides access to, any information pursuant to his employment or contract with the Commission, or his employment with such contractor.

Printed in USA. Price $\$ 1$. Available from the Clearinghouse for Federal Scientific and Technical Information, National Bureau of Standards, U. S. Department of Commerce, Springfield, Virginia 


\title{
IMPROVED ELECTRODELESS TOROIDAL CONDUCTIVITY ANALYZER
}

\author{
by
}

\section{M. Johnson}

G. E. Hart

THE DOW CIIEMICAL COMPANY ROCKY FLATS DIVISION

P. 0. BOX 888

GOLDEN, COLORADO 80402

U. S. A TOMIC. ENERGY COMMISSION CONTRACT AT(29-1)-1106 
RFP -657

\section{ACKNOWLEDGMENT}

The authors wish to acknowledge the assistance of G. J. Cunningham whose background in toroidal analyses was very helpful. 


\begin{abstract}
An improved electrodeless toroidal conductivity analyzer has been designed and constructed. Improvements in the instrument sensitivity were achieved by frequency tuning, modified toroidal configuration, and increased core mass. Improvements in instrument design were achieved by transistorized circuitry, including automatic temperature compensation.
\end{abstract}


RFP -657 
SUMMARY

The investigation of the toroidal type analyzer resulted in several conclusions. Each toroid had a resonant frequency at which maximum sensitivity was achieved. This frequency was a function of the core mass, number of turns in the winding, and wire size of the winding. Material of construction of the core was also an influencing factor. The best configuration of toroids consisted of two driving and one sensing toroid. The driving toroids should be electrically connected in parallel. By increasing, the mass of core material used in the toroid, an increase in transformer efficiency was realized. The increased mass facilitated the energy transfer from the driving toroid to the sensing toroid. Optimum intertoroidal spacing was a function of the flux field produced by the driving toroid. Intertoroidal spacing was not critical if the sensing toroid was kept within the major flux field of the driving toroid. Increased electrolyte temp- . eratures resulted in increased toroidal output, and the point of . . s inflection of the normality curve was shifted as a result of increased. ionic mobility.

A phase shift oscillator powered the driving toroids, and the resulting signal impinged on the sensing toroid was amplified by a 2-transistor a-c amplifier. Temperature compensation was achieved by automatic amplitude correction from a thermistor sensor.

\section{INTRODUCTION}

Conductivity analysis is used as a control parameter on various solutions at Rocky flats. The toroidal analyzer has been used to. determine acid content of plutonium-bearing solutions.

Commercial toroidal analyzers have cost $\$ 1,150.00$ each as compared to $\$ 350.00$ for Rocky Flats produced analyzers. Economic and utility considerations were implemental in starting the investigation for a better and less expensive analyzer. 
The toroidal type conductivity analyzer operates on the following principle. The energy produced at a driving toroid is transferred through an electrolyte to a sensing toroid. The energy transfer is proportional to the concentration of the electrolyte until additions of solute impede that transfer. At this point decreased dilution and ionic mobility cause decreased energy transfer and depression of the conductance normality curve.

The law of independent migration of ions affects the toroldal conductivity analyzer as it does all conductivity analyzers. However, because the hydrogen ion is the prime variable, and its ionic conductance is much greater than other ions that might be present, it is postulated that other ions would have reduced effect. Only an elementary investigation to verify and confirm this relationship was performed. ${ }^{2}$

The electrodeless toroidal type conductivity analyzer has been in use at Rocky Flats since 19592,3,4. In reviewing the literature a comprehensive study of the physical parameters could not be found. The purpose of this project. was to examine and optimize the physical and electrical parameters of the toroidal analyzer.

1. S. Glasstone, Textbook of Physical Chemistry, D. Van Nostrand Company, Inc., Princeton, N. J., (2nd Ed.), 8́94-895(1946).

2. G. A. Rost, "Ac1dity Determination of" Plutonium Peroxide Slurries Using a Toroidal Conductivity Method," Rocky Flats Internal Report AMD 365-1, August 1959.

3. G. J. Cunningham and K. I. Hawkins, "A Toroidal Conductivity Apparatus for Measurements of Acid Concentrations," Rocky Flats Internal Report 940621-6, July 1964.

4. C. M. Johnson and G. E. Hart, "An Improved Toroidal Conductivity Analyzer," Rocky Flats Internal Report CRDL 940233-103, June 11, 1965. 
EXPERIMENTAL

FREQUENCY

The primary element of the analyzer is the toroid. The toroid is an inductive device which has maximum energy transfer characteristics at its resonant frequency. To determine resonant frequencies, two toroids were assembled having equal core and winding characteristics. The driving toroid was connected to a variable frequency oscillator with constant voltage output. The sensing toroid was connected to a 2-transistor amplifier with meter readout (see Figure 1): A conductor was placed in the center of the toroids to facilitate energy transfer. A 10-turn 100-ohm potentiometer was connected in series with the conductor to simulate a variance of electrolyte conductance. At a given frequency the resistance in the conductor was varied to give ten values on the meter readout of the sensing toroid. The frequency was then changed and the test repeated. For a given pair of toroids a family of curves was obtained that showed maximum sensitivity at a particular frequency (see Figure 2). Various toroids were tested.

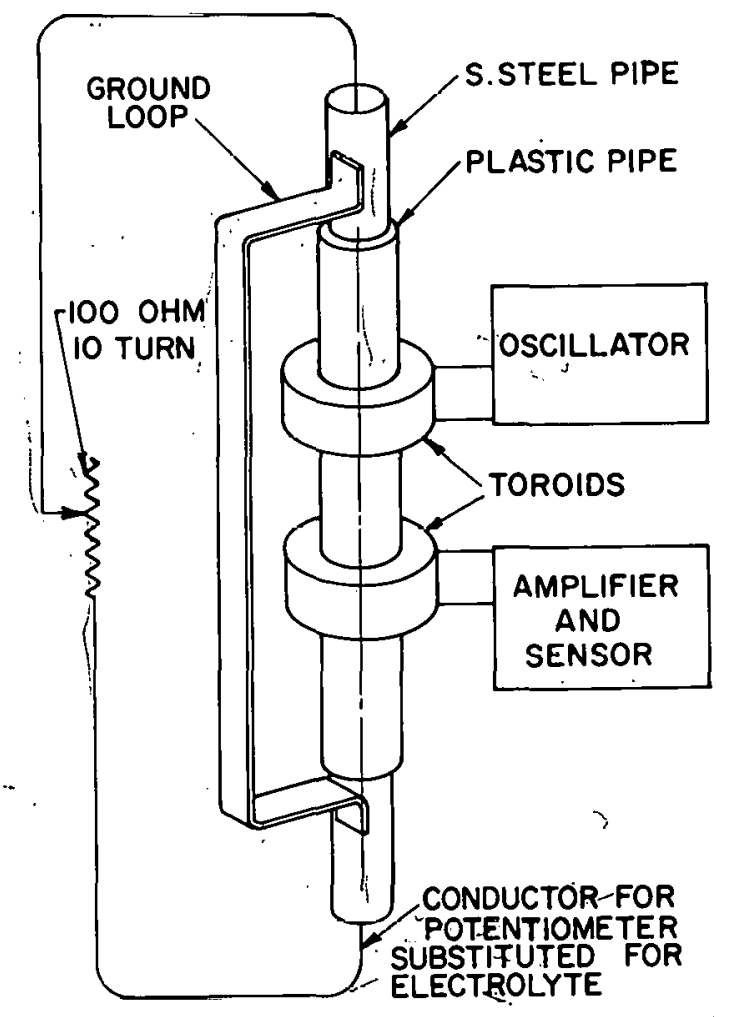

Figure 1. CONVENTIONAL TOROIDAL ANALYZEER SENSING UNIT 


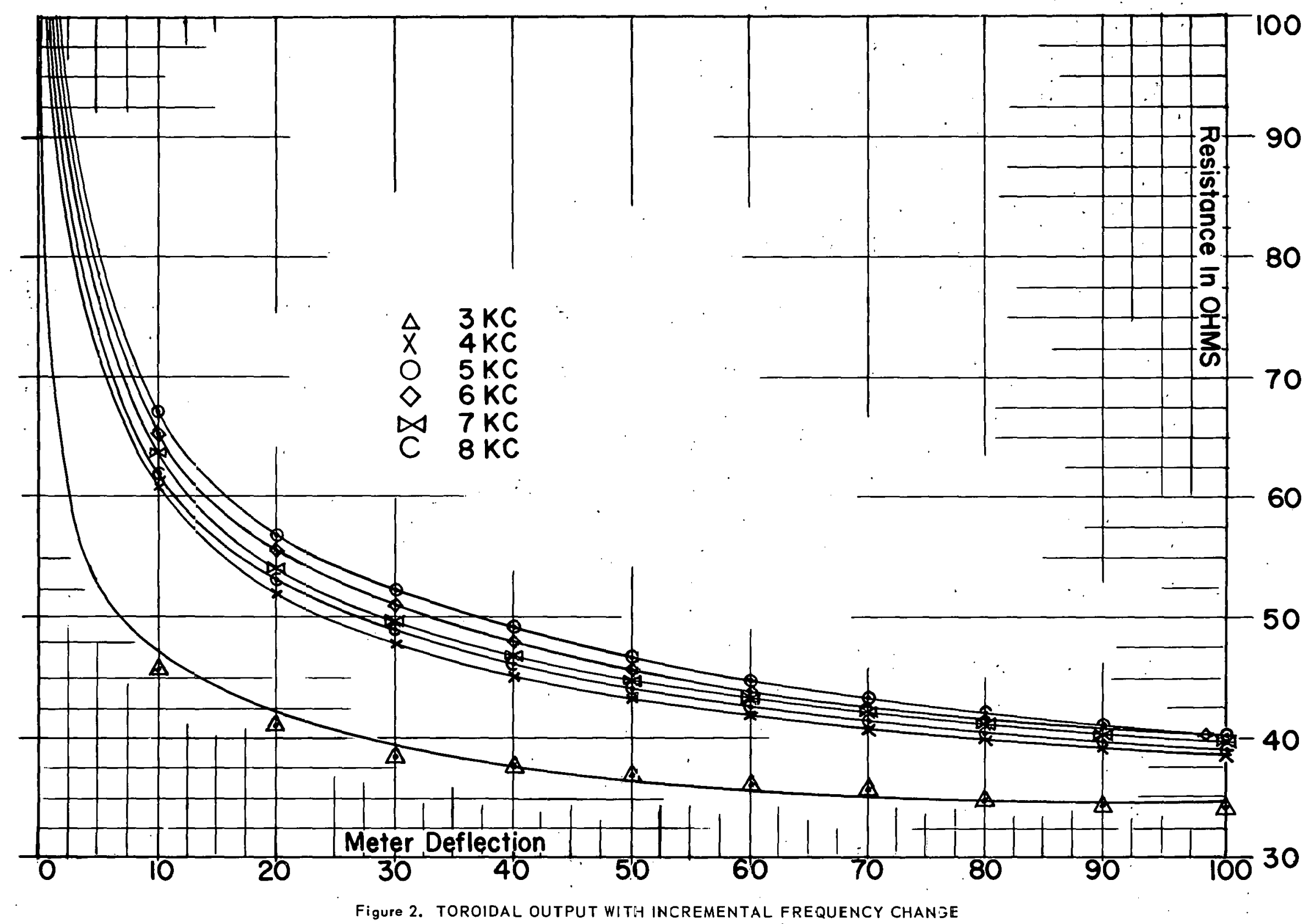

Figure 2. TOROIDAL OUTPUT WITH INCREMENTAL FREQUENCY CHANSE 
The resonant frequency of a set of toroids was a function of the core size, number of turns in the winding, and the wire size of the windings. Maximum energy transfer for a particular set of torolds at a particular set of conditions was realized at the resonant frequency of that set.

\section{CONFIGURATION}

The next parameter to be examined was toroidal configuration. Classically, the toroidal analyzer has consisted of one driving toroid and 1 sensing toroid. Additional toroids were added to the driving and sensing element of the analyzer. Various series and parallel wiring systems were tried. The best combination was two driving toroids, which were wired in parallel, with the sensing toroid in the center (see Figure 3). An increase in output at the conductance curve maximum from 0.10 to 0.20 volt was realized (see Figure 4). Further stacking of toroids showed little increase in sensitivity.

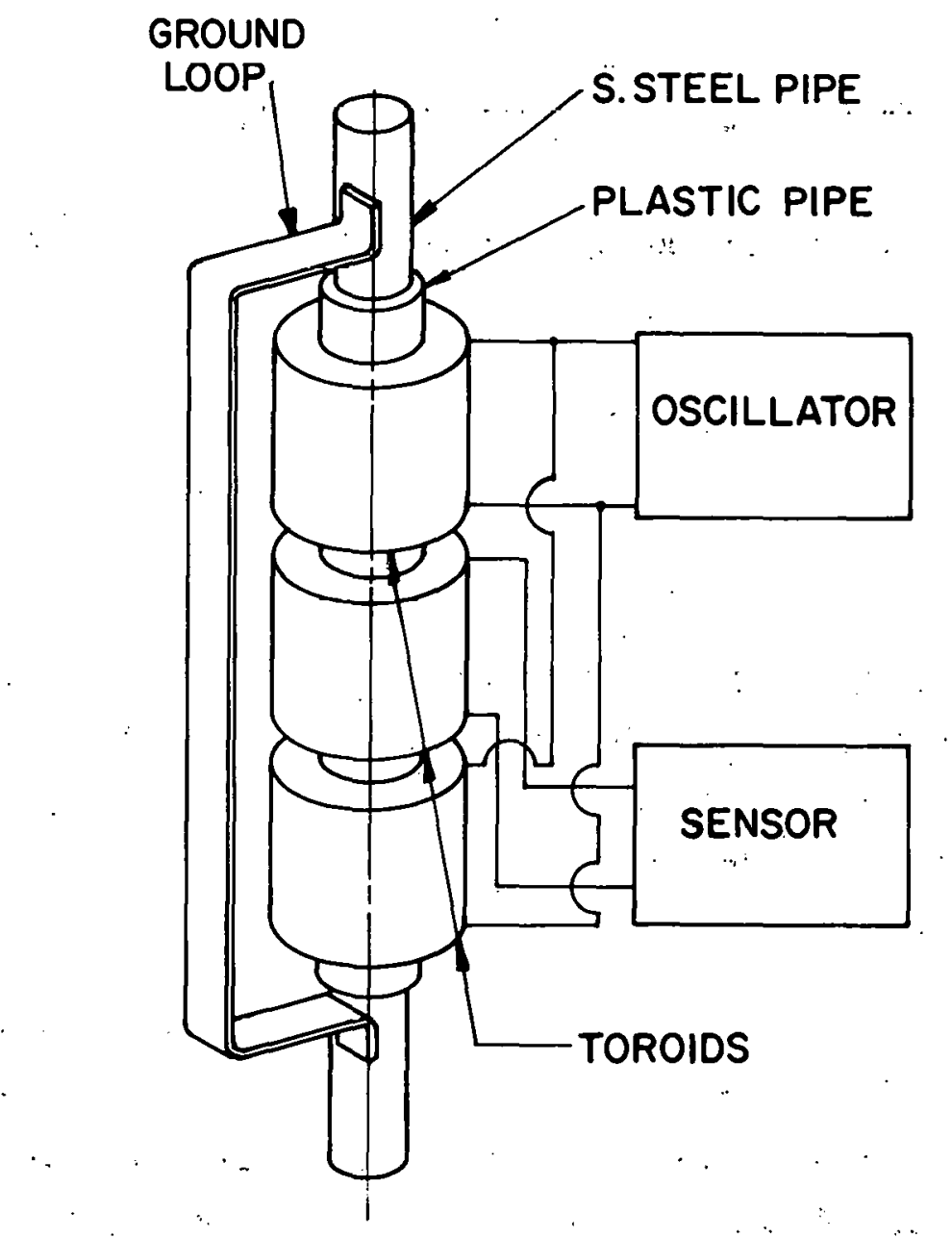

Figure 3. IMPROVED TOROIDAL ANALYZER SENSING UNIT 


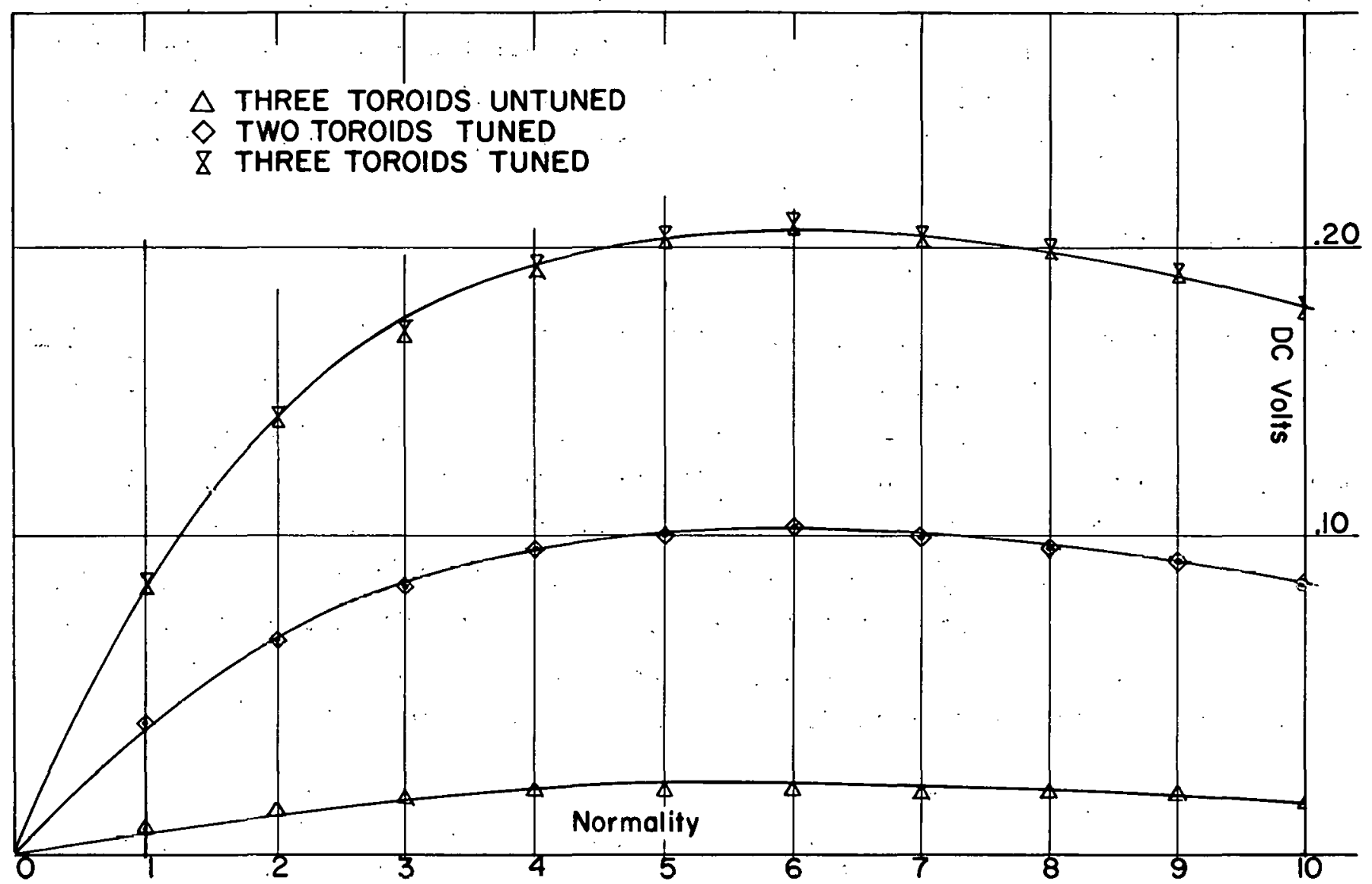

Figure 4. TOROIDAL OUTPUT WITH DIFFERENT CONFIGURATIONS

CORE MASS

The size or mass of the core of a torold has an appreciable effect on the energy it will produce or detect. Cores of $0.25 \mathrm{in}$. by $0.25 \mathrm{in}$. cross section have been used on most analyzers at Rocky Flats. Toroids of dif'ferent diameters have been used, but the mass of the cores has not varied greatly.

By taping several cores together before winding, an increase in core mass was achieved. The increase in mass caused an increase in energy transfer. Cores with a cross section of 0.25 in. by 1.0 in. were obtained and tested. A threefold increase in the output voltage was obtained (see Figure 5). 


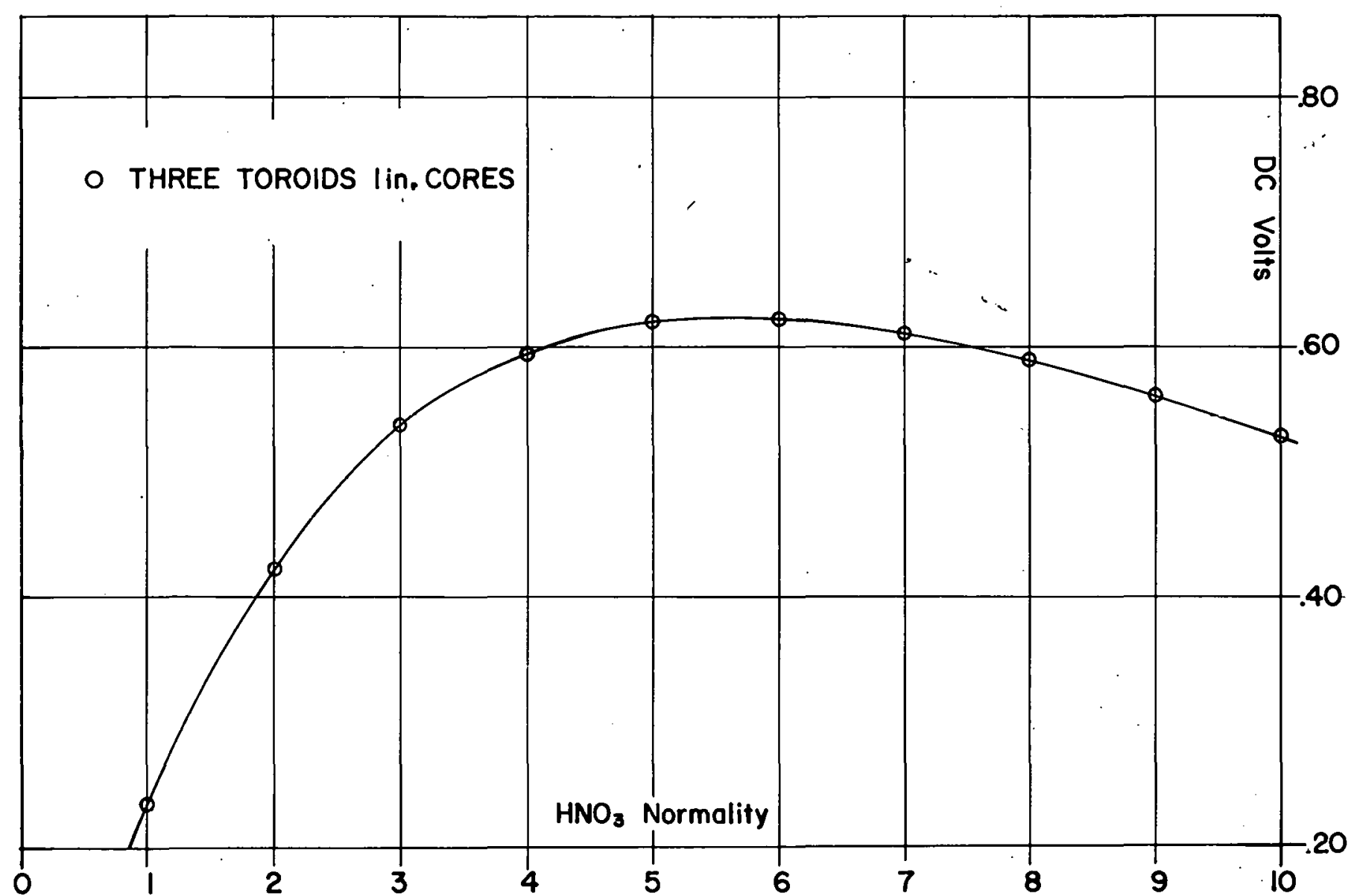

Figure 5. TOROIDAL OUTPUT AT OPTIMUM CONFIGURATION

DISTANCE BETWEEN CORES.

The sensitivity of the analyzer is a function of the energy transfer. An area of maximum transfer efficiency should exist when the toroids are an optimum distance apart. This optimum distance occurs anywhere within the major flux field of the driving toroids. In order to test this, all experimental conditions were held constant and the distance between toroids was increased by 0.25 in. increments. The sensitivity of the toroids remained constant until the sensing toroid was out of the major flux field of the driving toroid, and it decreased. The major flux field of the driving toroid could be increased by increasing the voltage applied to it, but the sensitivity correlation 
remained. It was concluded that no improvements could be realized by distance optimizing, except that the sensing toroid must be in the major flux field of the driving toroid.

\section{TEMPERATURE EFFECTS}

The effects of electrolyte temperature on the output of the sensing toroid were examined (see Figure 6). Increased temperature produces increased conductivity, therefore the family of curves followed a predictable pattern. The inflection of the curve maxima was shifted to a slightly higher normality as the temperature increased. 'l'hi's is attributed to increased ionic mobility. A slight increase in sens1tivity could be realized by operating the cell at $30^{\circ} \mathrm{C}$. The increased

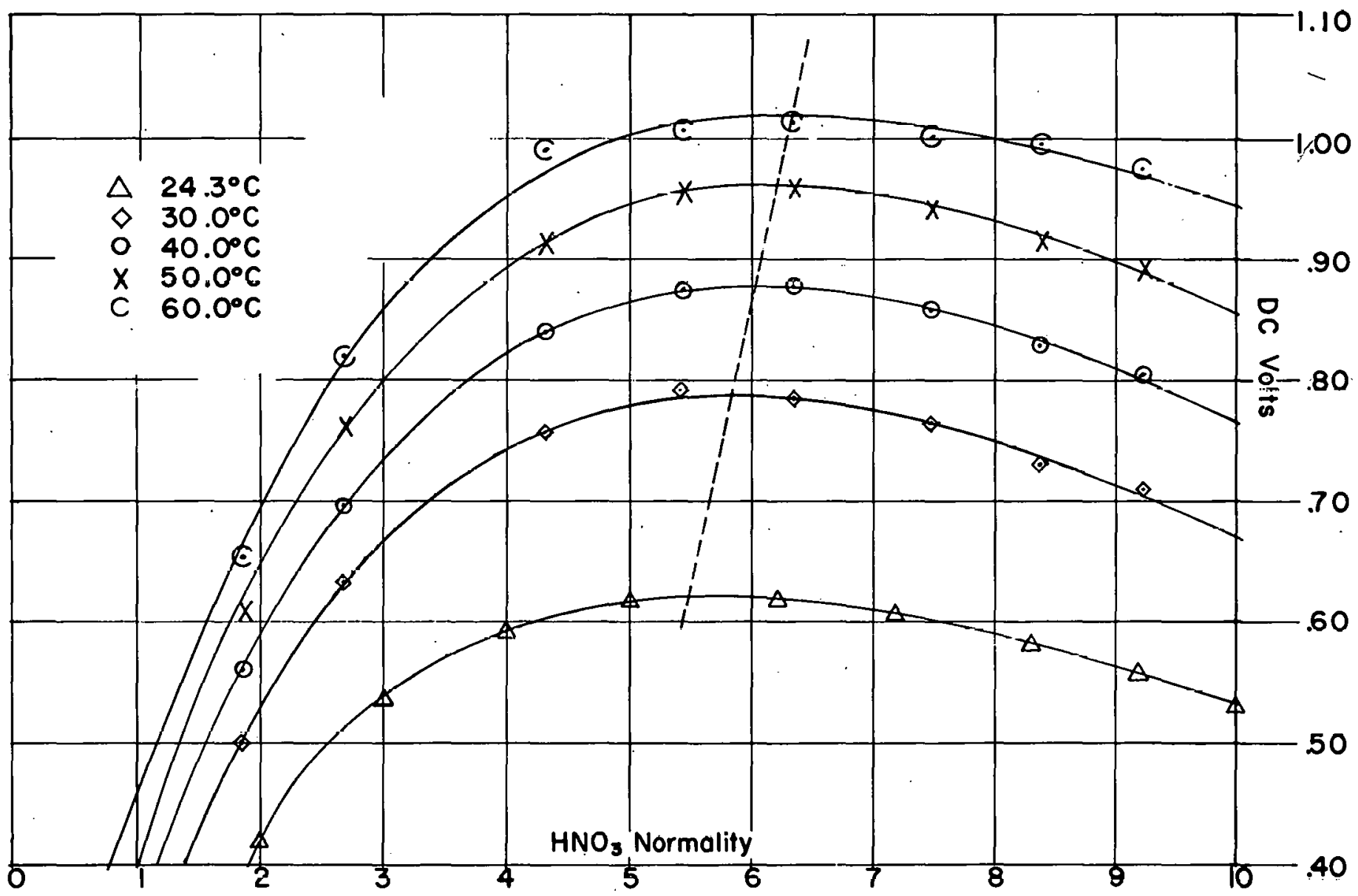

Figure 6. TOROIDAL OUTPUT AT VARIOUS TEMPERATURES 
complexities of a constant temperature cell would not justify the benefit derived from it.

\section{TRANSISTOR CIRCUITRY}

Commercial toroidal. analyzers use vacuum tube circuits and are designed for limited applications. The transistor circuitry used in the Rocky. Flats toroidal analyzer enables the instrument to be used over a broad range of conductivities.

The transistor circuits used in the toroidal analyzer consist of a phase shift oscillator and a 2-transistor a-c amplifier (see Figure 7). Temperature compensation is achieved by amplitude control in the amplifier employing a thermistor as a sensor.

The phase-shift oscillator uses a resistor-capacitor (RC) feedback network to sustain oscillation. Each RC section contributed a phase shift of 60 degrees at the frequency of oscillation; so that the signal at the collector of the transistor is $180^{\circ}$ out of phase with the signal at the base. This fulfills the regenerative feedback conditions to generate and sustain oscillation at a selected frequency.) The RC sections are selected for the desired frequency of operation. The variation of frequency is achieved by using a variable resistance in one of the $\mathrm{RC}$ sections, thus enabling using of the desired frequency under actual operating load conditions.

The a-c amplifier consists of two RC coupled stages designed to pass and amplify the particular frequencies of interest. Positive feedback is utilized to compensate for any gain loss due to degeneration! Circuit design considerations (include d-c stabilization, increased input impedance, and minimized distortion by introduction of a slight amount of inverse feedback.)

(A potentiometer at the input of the amplifier allows a variable amount of toroid output signal to be selected. This gain control permits the amplifier to be used at different ranges of conductivities for versatility. 


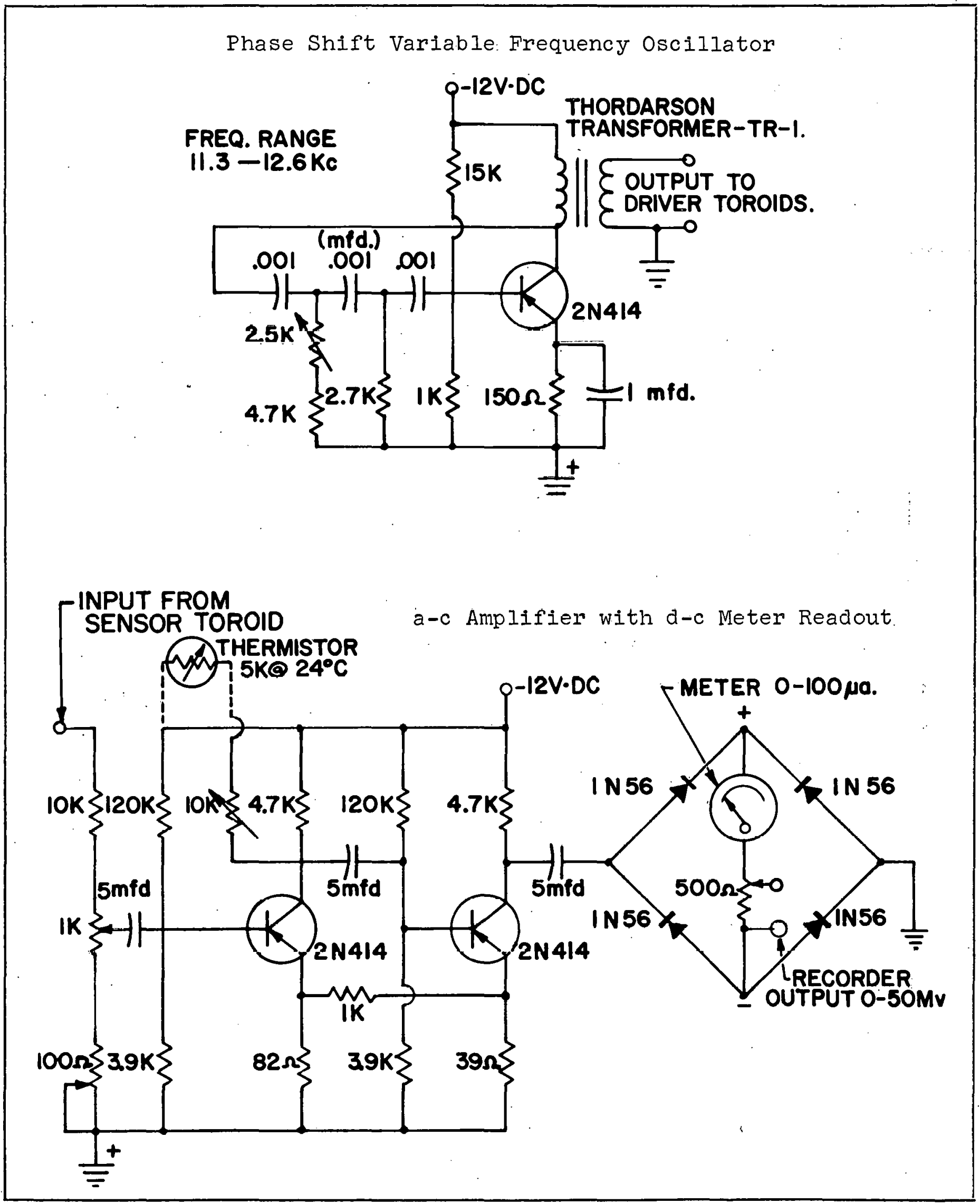

Figure 7. TRANSISTOR ELECTRONIC CIRCUITRY OF THE ROCKY FLATS TOROIDAL ANALYZER 
Automatic temperature compensation is achieved by varying the load resistance of the first transistor stage, thus affecting the amplitude of the signal presented to the second transistor stage and consequently the meter readout.

The value and characteristics of the thermistor sensor and the series potentiometer in the thermistor circuit determine the amount of temperature compensation.

It was concluded that improvements can be made in existing toroidal conductivity analyzers. Frequency tuning, correct toroidal configuration, increased core mass, and improved transistor circuitry will accomplish these.

The improved toroidal analyzer is depicted in Figures 8, 9, and 10. Figure 8 shows an exposed toroidal cell with one in. cores and correct configuration. Figure 9 shows the electronic circuitry, and Figure 10 shows the total instrument in use. 


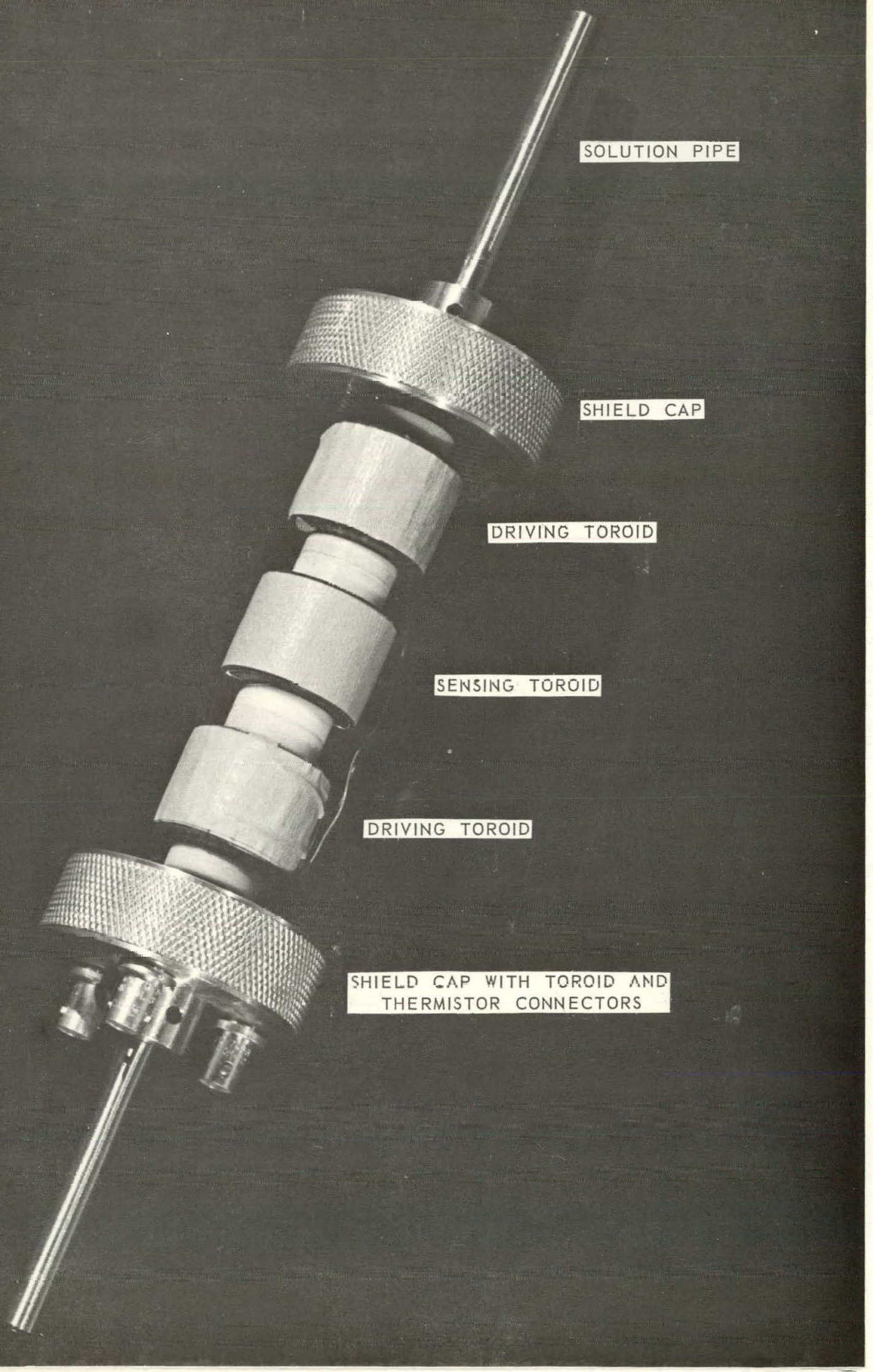

Figure 8. IMPROVED TOROIDAL CELL 


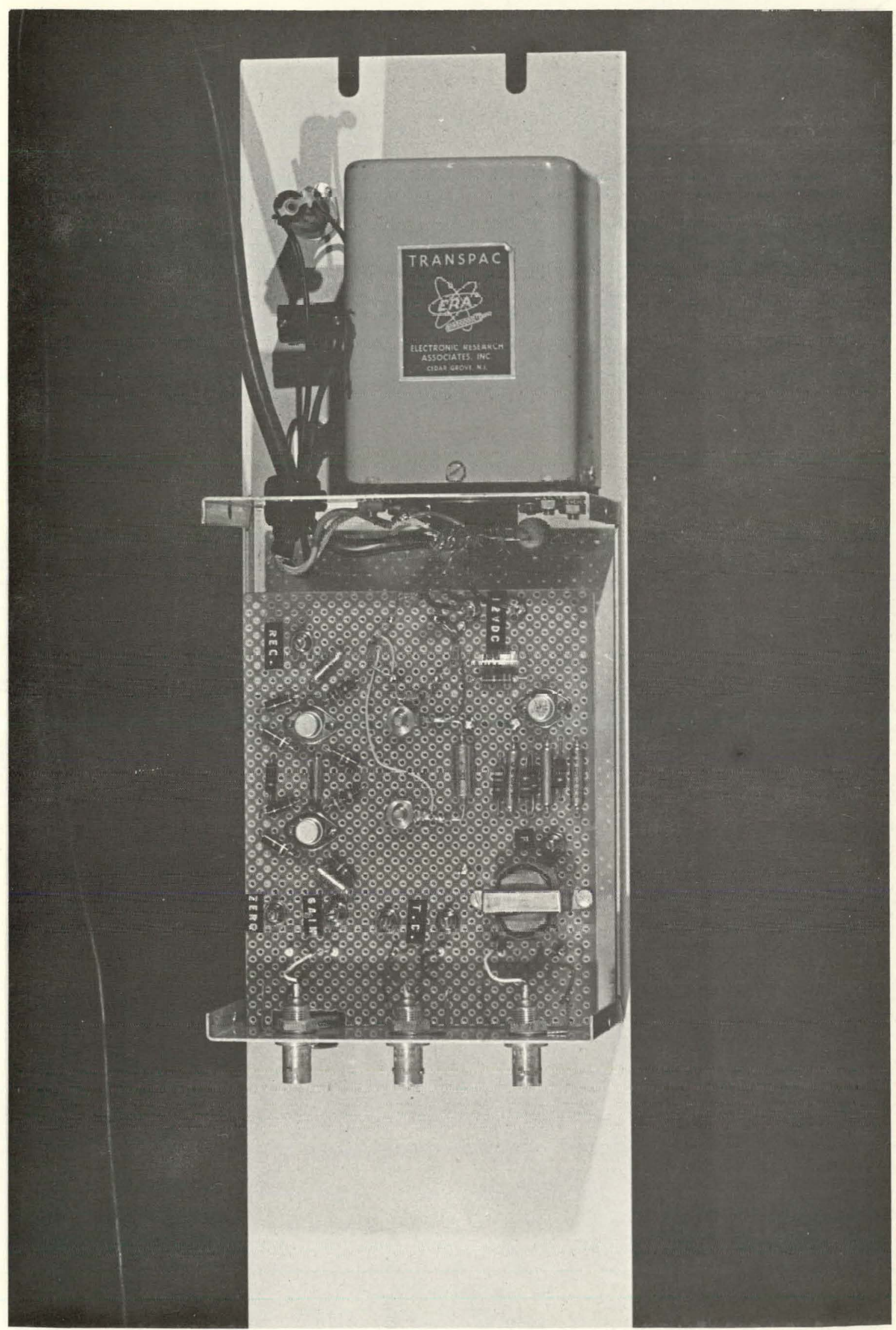

Figure 9. ELECTRONIC CIRCUITRY 


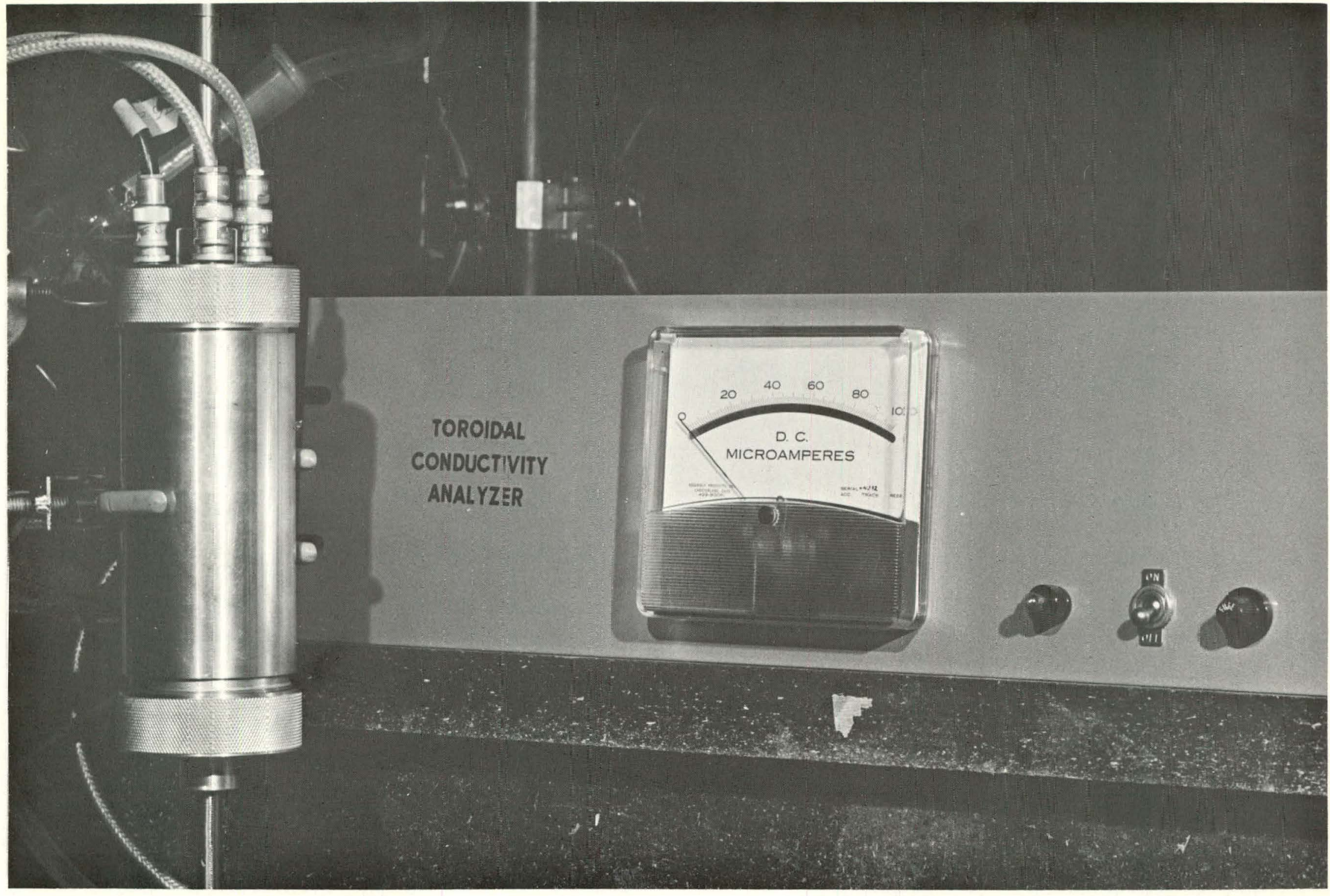

